\title{
Knowledge Enhancement of Aceh Province Coaches on Basic Life Support Material
}

\author{
Yusni Yusni ${ }^{1, *}$, Muhammad Ridwan ${ }^{1,2}$, Amiruddin Amiruddin ${ }^{3}$ \\ ${ }^{1}$ Department of Physiology, Faculty of Medicine, Universitas Syiah Kuala, Banda Aceh, Indonesia \\ ${ }^{2}$ Department of Cardiology Faculty of Medicine, Universitas Syiah Kuala/dr. Zainoel Abidin Hospital Banda Aceh, Indonesia \\ ${ }^{3}$ Physical Education, Health and Recreation, Universitas Syiah Kuala, Banda Aceh, Indonesia
}

Received April 23, 2021; Revised June 16, 2021; Accepted July 18, 2021

\section{Cite This Paper in the following Citation Styles}

(a): [1] Yusni Yusni, Muhammad Ridwan, Amiruddin Amiruddin, "Knowledge Enhancement of Aceh Province Coaches on Basic Life Support Material," International Journal of Human Movement and Sports Sciences, Vol. 9, No. 4A, pp. 38 44, 2021. DOI: 10.13189/saj.2021.091307.

(b): Yusni Yusni, Muhammad Ridwan, Amiruddin Amiruddin (2021). Knowledge Enhancement of Aceh Province Coaches on Basic Life Support Material. International Journal of Human Movement and Sports Sciences, 9(4A), 38 - 44. DOI: 10.13189/saj.2021.091307.

Copyright $\bigcirc 2021$ by authors, all rights reserved. Authors agree that this article remains permanently open access under the terms of the Creative Commons Attribution License 4.0 International License

\begin{abstract}
Objective: The research objective was to analyze the effect of providing material about Basic Life Support (BLS) on increasing the knowledge of coaches. Methods: This study was an experimental study with one group pretest and posttest design. Subjects of the study were 10 male coaches from Aceh Province, aged 22-32 years, from 5 different types of sport, namely Rugby, athletics, Taekwondo, Archery, and Karate. Data analysis used descriptive analysis, chi-square $(\mathrm{p}<0.05)$, and paired sample t-test $(\mathrm{p}<0.05)$. The results showed that the average age was 26.7 years. $30 \%$ of the subjects had a high school degree, $50 \%$ of the subjects had undergraduate degree, and $20 \%$ of the subjects had a Master degree. The level of coach's knowledge about BLS was increased by $40.37 \%$ after receiving material about BLS. The knowledge level of the coaches was different before and after receiving education about BLS (56.67 and 79.55; $\mathrm{p}=0.001)$. It was also related to the level of education $\left(\mathrm{x}^{2}=0.007 *\right)$. Conclusions: The level of the coach's knowledge about BLS is related to education level. The coaches with undergraduate degree had better knowledge than others. The study concludes that providing BLS materials could effectively improve the knowledge level of the coaches from Aceh province.
\end{abstract}

Keywords Coaches, Athletes, Basic Life Support, Aceh Province

\section{Introduction}

Sudden death due to sudden cardiac arrest (SCA) often occurs in athletes while training and competing, which is the etiology is unclear [1]. SCA is called sports or athletes who do not have experience with any health problems for 6 hours before the death, suddenly and generally, which is one hour after or during exercise with or without trauma [2]. A prospective study reported that the incidence of SCA in athletes was 2.3/100,000 per year [2]. $40-50 \%$ of deaths in athletes are caused by SCA, and Basic Life Support (BLS) is the first aid and a critical effort to save lives and improve the prognosis of patients with cardiac arrest [3-6]. Several risk factors of SCA include environment, family history and genetics, health conditions, and intense physical exercise [1]. Athletes are groups that have exposure to sudden death caused by cardiac arrest, thus BLS knowledge should be owned by the athletes and coaches [1].

Knowledge of BLS should not only be possessed by health professionals but also other related professions, including families at high risk of cardiac arrest, undergraduate students from sports science, sports teachers, and coaches [7-9]. The coach is the person closest to the athlete, so the coach's knowledge of BLS will help in handling athletes during emergency conditions due to sports injuries [1,10]. It will help impact mortality and morbidity from sports injuries [1]. The risk of injury of athletes increases not only because of the high 
intensity of the sport but also due to the high frequency or duration of training that results in fatigue [11]. BLS is a part of medical skills that are needed by coaches in emergency situations to save athletes' lives [3,12].

Exhausting and high-intensity sports, such as karate and Taekwondo, have a high risk of sudden death occurrence, thus it requires a coach who has a good knowledge of BLS and even highly advisable to have a BLS certification and first aid for trainers $[1,10]$. Sometimes, trainers are required to be able to handle emergency conditions where health workers are unavailable and health service facilities are difficult to reach [10]. Conversely, although the risk of injury in athletics is lower than in martial arts, sports injuries can occur without any prediction, in consequence, the knowledge of BLS is also needed for athletic trainers [13]. Providing materials and skills is an effective way to increase knowledge about BLS [14,15]. Analysis of the level of knowledge and provision of material about BLS for athlete coaches is needed to formulate a BLS training plan and program as an effort to prevent morbidity of athletes and also for fellow trainers. This study aimed to analyze the level of knowledge and the effect of BLS teaching on increasing knowledge of athlete coaches in Aceh Province.

\section{Methods}

This study was a quasi-experimental study with pretest and posttest without a control group design. The research subjects were athlete coaches from Aceh Province in several types of sports, such as Taekwondo, Rugby, Athletics, Archery, and Karate. The number of subjects was 10 people. The determination of the value of samples is based on total population sampling. Initially, the subjects were 12 trainers, but one day before the implementation of the study, 2 subjects complained of fever, cough, and the body temperature above normal $\left(>38^{\circ} \mathrm{C}\right)$. Wherefore both subjects were excluded from the study because they experienced symptoms of Covid-19. The determination of the number of samples was calculated based on the sample calculation formula for experimental research. 10 samples had met the minimum sample size for this research design.

The criteria for the subject were a trainer, aged between 20-35 years, male, active in training, healthy, not currently suffering from Covid-19 based on laboratory examination results, not experiencing fever (based on the results of a body temperature examination using a thermal gun), not experiencing symptoms related to Covid-19, such as feeling unwell, chills, nausea, vomiting, diarrhea, fatigue, muscle pain, etc., willing to be a subject by adhering to health protocols during the implementation of activities, and following all stages of research considered applicable to all subjects.

The subject received an explanation about BLS through a projector LCD. The material was only given once with 45-60-minute duration, including discussion and question and answer. The questionnaire was given before and after the provision of material about BLS to determine the subject's level of knowledge about BLS. The questionnaire consisted of 18 questions and all of which were related to BLS. The material was given directly (face to face) at the Syiah Kuala University student dormitory on October 25, 2020. The material was given by a cardiologist who was an expert in the field of BLS. This research was approved by the Research Ethics Committee of the Faculty of Medicine, Universitas Syiah Kuala with number: 272/EA/FK-RSUDZA/2020.

Statistical analysis: Data analysis was conducted using descriptive analysis, chi-square for correlation, and paired sample t-test to determine the effect of explanations about BLS on increasing the subject knowledge. Chi-square correlation analysis aimed to determine the relationship between the education and knowledge levels of the coaches. The level of knowledge was categorized into three categories: score between 76-100 (good), 56-75 (moderate), and $<56$ (poor).

\section{Results}

The results of the study regarding the age characteristics of the subjects are shown in Figure 1. The ages of the subjects ranged from 22-32 years; the youngest was 22 years old, while the oldest was 32 years old. The mean of the subject age was 26.7 years. 


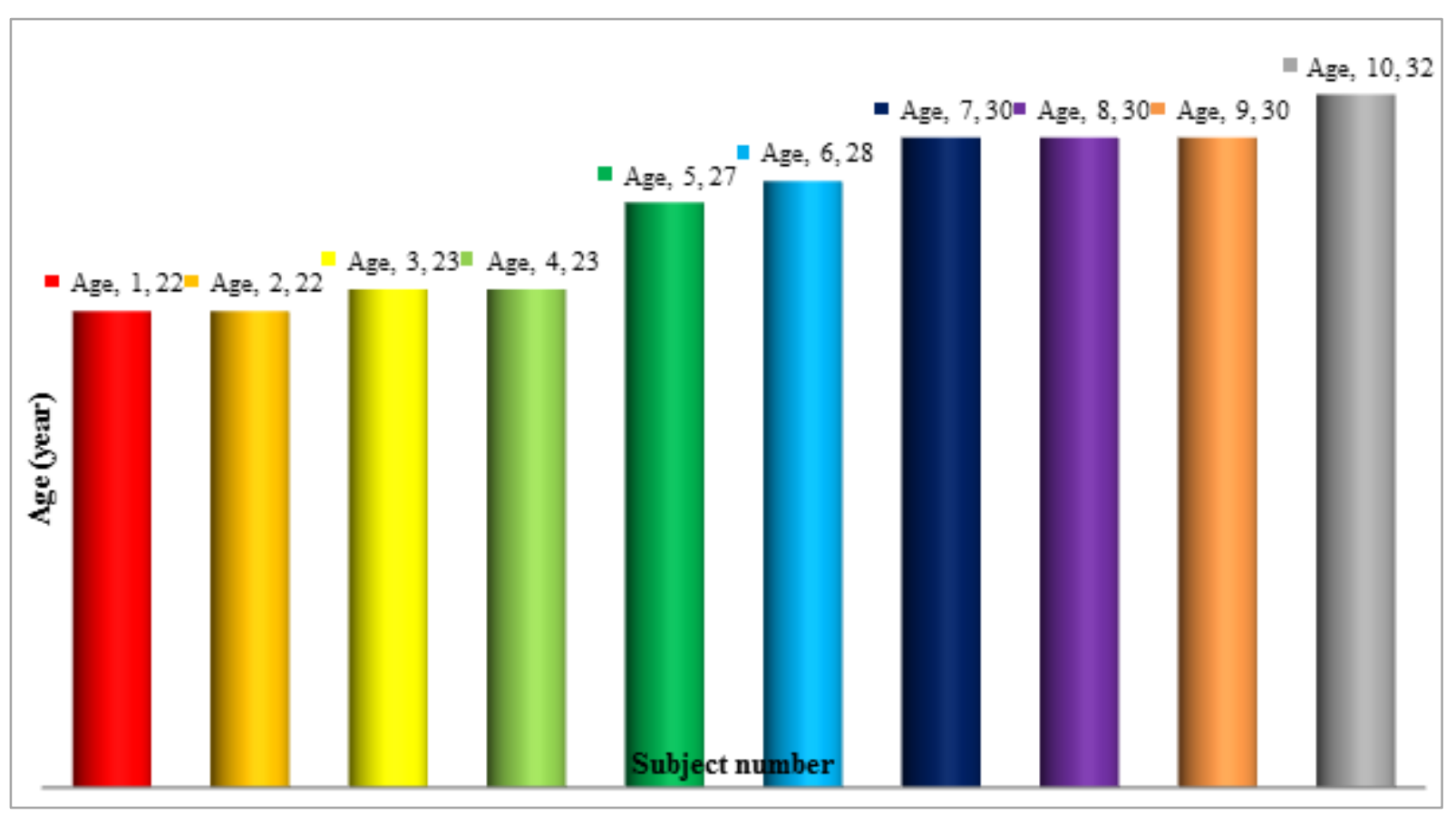

Figure 1. Characteristics of Subjects by Age

The level of education of the subject can be seen in Figure 2. The largest number of subjects was undergraduate level $(50 \%)$ from sports education. Moreover, the number of subjects with a Master degree in sports education was the smallest $(20 \%)$.

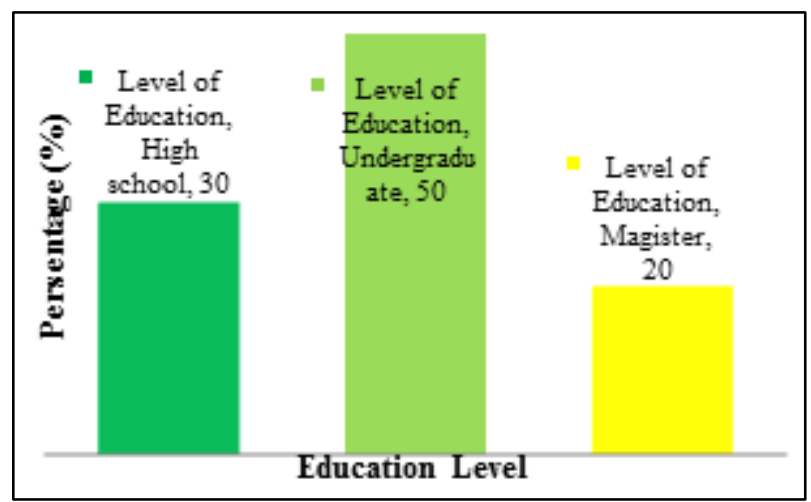

Figure 2. Characteristics of Subjects based on the Education Level

Figure 3 provides an overview of the characteristics of the subject based on type of sport. The subjects were coaches of 5 sports, namely Rugby, athletics, Taekwondo, Archery, and Karate. Of the five types of sports, two of them were from martial arts, namely Taekwondo and Karate. Both sports are body contact sports that have a high risk of sports injuries, thus the knowledge of BLS is needed. The three other types of sports were non-body contact sports which also had a risk of sports injuries, which are sometimes unpredictable.

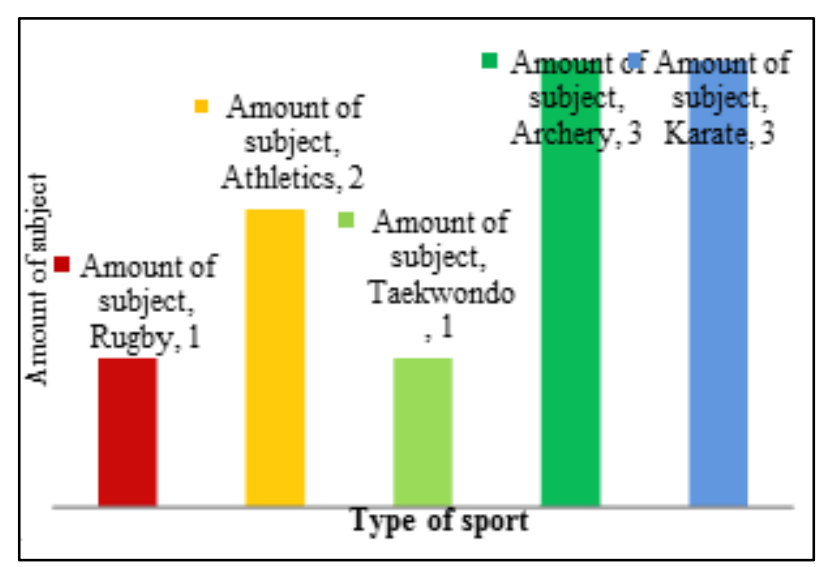

Figure 3. Subject characteristics by type of sport

Figure 4 describes the subject's level of knowledge before and after the explanation of the material about BLS. The results showed that the knowledge level of coaches was 38.89 (poor-category) before BLS teaching was conducted, while the highest was 66.66 that is equivalent to the moderate category. This score has increased to $85.7 \%$ after the material about BLS was explained by a cardiologist. The increase in this score was significant ( $\mathrm{p}>0.05$ ), as shown in Figure 5. 


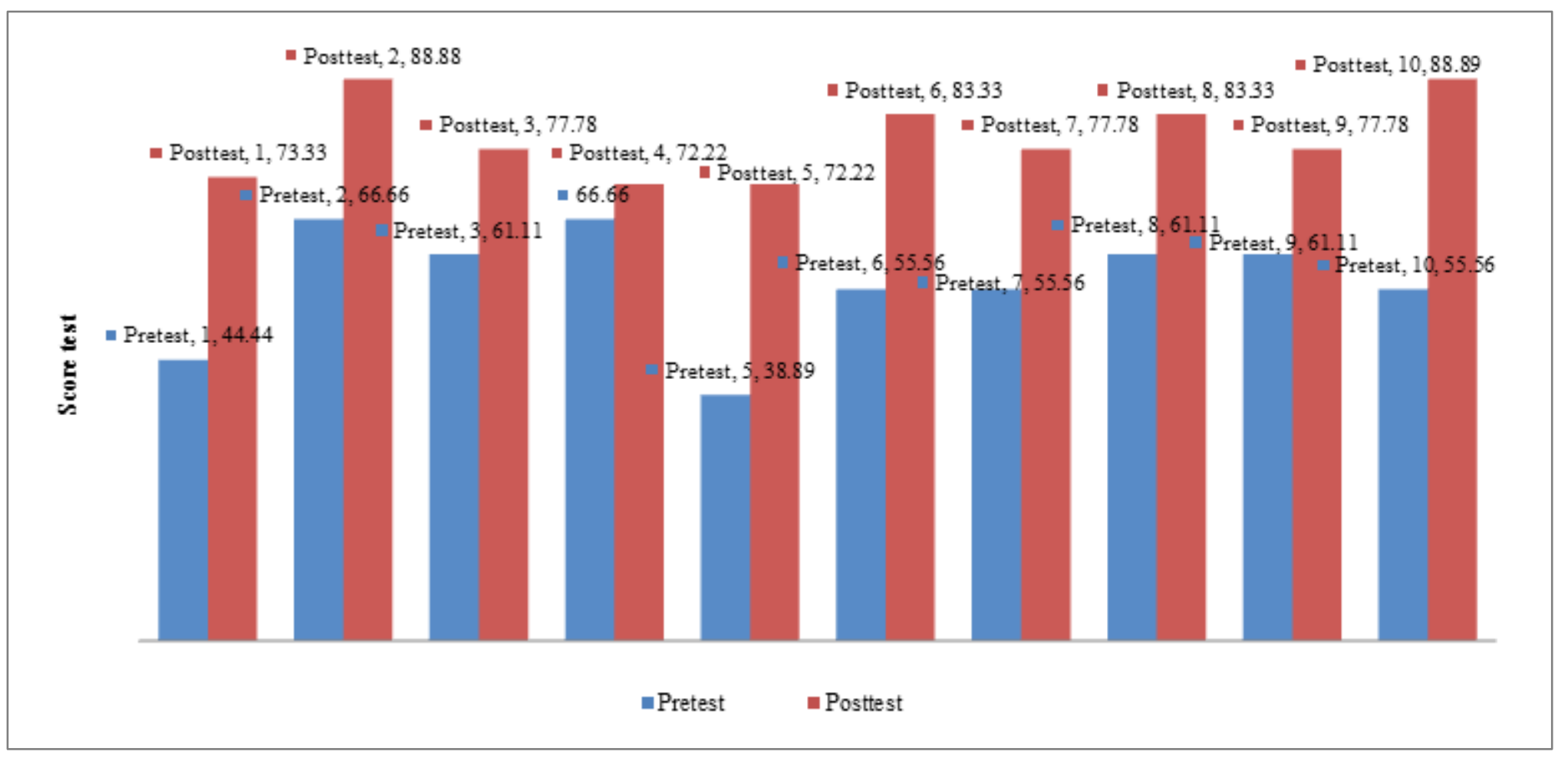

Figure 4. Overview of Subject Knowledge Before and After Provision of BLS Material 
The effect of BLS teaching on increasing knowledge of coaches was analyzed using paired sample t-tests and shown in Figure 5. The results showed that there was a significant difference between the coaches' level of knowledge before and after BLS teaching $(\mathrm{p}=0.001)$. This result indicates that giving explanations about BLS material has been proven to increase coaches' knowledge. These findings indicate that the level of trainers' knowledge about BLS was low. Furthermore, it is necessary to increase the knowledge and skills of coaches about BLS. BLS knowledge is needed to assist athletes in handling sports injuries. The coach is the closest person who assists the athlete during training and competing, so that if the athlete experiences an injury, the coach must immediately handle it for first aid. Therefore, a good trainer's knowledge and skills about BLS will be very helpful to provide first aid in the event of a sports injury before getting medical help or further services at the health care centre.

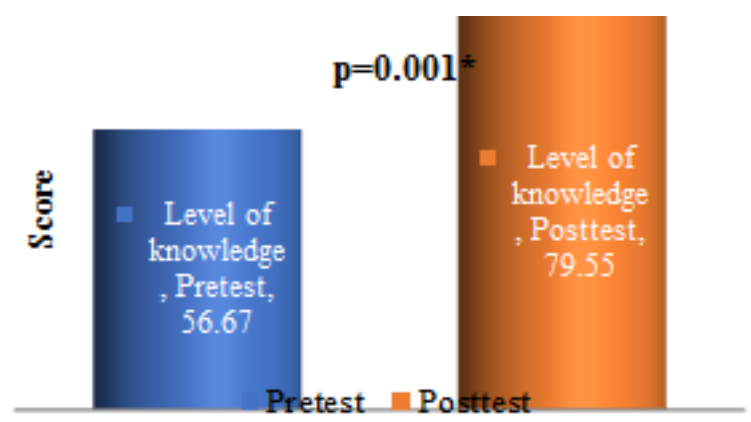

Figure 5. Subject characteristics by type of sport

The description related to the knowledge level of coaches both before and after giving material about BLS can be seen in Figure 6. The results show that there were no coaches with a good level of knowledge before the explanation of BLS material. This study found that $50 \%$ of the coaches had a knowledge level with poor-category before receiving the explanation of BLS material. The category changed after the explanation of the BLS material. The study found that $70 \%$ of the coaches had knowledge levels with a good category.

The effect of BLS teaching on increasing knowledge of coaches was analyzed using paired sample t-tests and shown in Figure 5. The results showed that there was a significant difference between the coaches' level of knowledge before and after BLS teaching $(\mathrm{p}=0.001)$. This result indicates that giving explanations about BLS material has been proven to increase coaches' knowledge. These findings indicate that the level of trainers' knowledge about BLS was low. Furthermore, it is necessary to increase the knowledge and skills of coaches about BLS. BLS knowledge is needed to assist athletes in handling sports injuries. The coach is the person closest to and always with the athlete during training and competing so that the knowledge and skills of BLS will be very helpful for providing first aid during sports injuries before getting medical assistance or further services.

The description related to the knowledge level of coaches both before and after giving material about BLS can be seen in Figure 6. The results show that there were no coaches with a good level of knowledge before the explanation of BLS material. This study found that $50 \%$ of the coaches had a knowledge level with poor-category before receiving the explanation of BLS material. The category changed after the explanation of the BLS material. The study found that $70 \%$ of the coaches had knowledge levels with a good category.

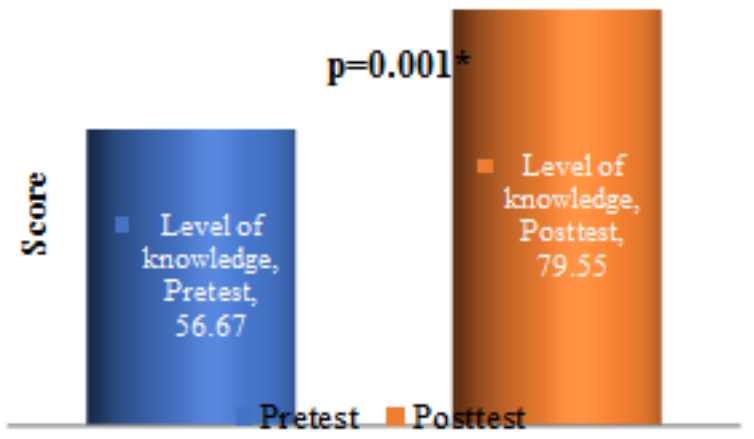

Figure 6. Classification of knowledge levels before and after receiving BLS explanation

The result of Chi-square analysis to determine the relationship between education and knowledge levels can be seen in table 1 . The results show that the knowledge level of coaches is related to the level of education. Coaches with an undergraduate degree have a better level of knowledge compared to coaches with high school and master education levels.

Table 1. Chi square analysis to determine the relationship between the level of education and the level of knowledge of the coach

\begin{tabular}{|c|c|c|c|c|c|c|c|c|c|}
\hline \multirow{3}{*}{ Education Level } & \multicolumn{8}{|c|}{ Knowledge Level } & \multirow{3}{*}{$x^{2}$} \\
\hline & \multicolumn{2}{|c|}{ Poor } & \multicolumn{2}{|c|}{ Moderate } & \multicolumn{2}{|c|}{ Good } & \multicolumn{2}{|c|}{ Total } & \\
\hline & $\Sigma$ & $\%$ & $\Sigma$ & $\%$ & $\Sigma$ & $\%$ & $\Sigma$ & $\%$ & \\
\hline High School & 3 & 30 & 0 & 0 & 0 & 0 & 3 & 30 & \\
\hline Bachelor & 0 & 0 & 5 & 50 & 0 & 0 & 5 & 50 & $0.007 *$ \\
\hline Magister & 2 & 20 & 0 & 0 & 0 & 0 & 2 & 20 & \\
\hline Total & 7 & 50 & 5 & 50 & 0 & 0 & 10 & 100 & \\
\hline
\end{tabular}




\section{Discussion}

Knowledge and skills about Basic Life Support should not only be possessed by health workers but also other professions, including athletes and coaches [7,16-19]. All athletes and coaches are at risk for sports injuries [20]. Both types of body contact and non-body contact sports are at risk for injury during exercising, training, and competing; therefore, the knowledge of BLS must be owned by all coaches. Knowledge of BLS, including first aid and cardiopulmonary resuscitation [CPR], is absolutely necessary for coaches to help athletes in both emergency, non-emergency, and SCA [21]. Every coach is required to participate in BLS training [22]. The coach is the first person who must respond immediately to the athlete's handling due to emergency conditions during training. Therefore, the knowledge of BLS is crucial for the coach $[10,19]$.

Sudden death in athletes during competition and training is rare, but can occur unpredictably; thus, education about BLS is needed for coaches [1]. The trainer is a person who is fully responsible for the athlete when training and competing, thus the knowledge of BLS is essential for the coach [23]. The results of our study indicate that the level of coaches' knowledge about BLS was low before receiving the material about BLS. Not only the coaches, but other researchers also found that the level of BLS knowledge was also low among health students [24].

We found that there was a significant increase in the level of knowledge of the trainers after the provision of material about BLS. Stella et al, states that the provision of knowledge and skills has been proven to be an effective way to increase the knowledge level of coaches about BLS [25]. Not only knowledge, but it is also required for every trainer to have the skills and trainer's certificate, especially related to injury management, including BLS $[13,21]$. The BLS procedure is urgently needed by athletes or coaches who have suffered life-threatening injuries [26]. BLS is needed by the coach because it can emphasize the risk of death and disability due to injury [27]. Training can also increase strength, aerobic and anaerobic performance so that it will reduce the risk of sports injury in athletes [28].

\section{Conclusion}

The level of education is related to the level of knowledge of coaches about BLS. The coaches with undergraduate education had a better knowledge level compared to high school and master degrees. Providing material about Basics Life Support can increase the knowledge level of the coaches. Therefore, it is necessary to provide regular BLS materials for them. Training on BLS is needed to equip trainers with skills in the first treatment of sports injuries.

\section{Acknowledgement}

The implementation of this research is funded by the Institute for Research and Community Service through a community service grant with contract number 34/UN11.2.1/PN.01.01/PNBP/2020. Accordingly, we would like to thank you for your assistance and support on research. We also thank all trainers who had volunteered to be the subject of this research. We express our sincere gratitude to the National Sports Committee of Indonesia (KONI) and Youth and Sports Service (Dispora) of Aceh Province who have become our partners in carrying out this research.

\section{Conflict of Interests}

This research and publication are conducted and approved by all research teams. Therefore, there is no conflict of interest in the publication of this article.

\section{REFERENCES}

[1] Vancini RL, Nikolaidis PT, Andre C, Lira B De, Vancini-campanharo CR, Viana RB, et al. Prevention of Sudden Death Related to Sport: The Science of Basic Life Support-From Theory to Practice. J Clin Med [Internet]. 2019; 8(556):1-19. Available from: www.mdpi.com/journ $\mathrm{al} / \mathrm{jcm}$

[2] Ozbilgin S, Kuvaki B, Hanc1 V, Ungur G, Tutuncu O, Koca $\mathrm{M}$, et al. Awareness and Attitudes to Cardiopulmonary Resuscitation Among Footballers; a Survey in Turkey Emergency Medicine: Open Access. Emerg Med Open Access. 2016;6(4):4-7.

[3] Ahmad A, Akhter N, Mandal RK, Areeshi MY, Lohani M, Irshad M, et al. Knowledge of basic life support among the students of Jazan University, Saudi Arabia: Is it adequate to save a life? Alexandria J Med [Internet]. Alexandria University Faculty of Medicine; 2018;xxx(xxx-xxx):1-5. Available from: https://doi.org/10.1016/j.ajme.2018.04.001

[4] Awadalla NJ, Humayed RS Al, Mahfouz AA. Experience of Basic Life Support among King Khalid University Health Profession Students, Southwestern Saudi Arabia. Int J Environ Res Public Health [Internet]. 2020;17(4822):1-7. Available from: www.mdpi.com/journal/ijerph

[5] Irfan B, Zahid I, Khan MS, Khan OAA, Zaidi S, Awan S, et al. Current state of knowledge of basic life support in health professionals of the largest city in Pakistan: a cross-sectional study. BMC Health Serv Res. BMC Health Services Research; 2019;19(865):1-7.

[6] Rodrı E, Abelairas-go C, Pen C, Ruano-ravin A, Rodrı A. Training adult lay people in basic life support. A systematic review. Rev Esp Cardiol [Internet]. 2020;73(1):53-68. Available from: https://doi.org/10.1016/j.rec.2018.11.013

[7] Aranda-garc S, Herrera-pedroviejo E, Abelairas-Gómez C. Basic Life-Support Learning in Undergraduate Students of 
Sports Sciences: Efficacy of 150 Minutes of Training and Retention after Eight Months. Int J Environ Res Public Health. 2019;16(4771):1-11.

[8] Cartledge S, Bray J, Leary M. A systematic review of basic life support training targeting family members of high-risk patients. Resuscitation [Internet]. Elsevier Ireland Ltd; 2015;96:59.

[9] Ojifinni K, Motara F, Laher AE. Knowledge, Attitudes and Perceptions Regarding Basic Life Support Among Teachers in Training. Cureus. 2019;11(12):1-13.

[10] Chin JW, Castro L. Assessment of Coaches' First Aid Knowledge and Decision Making in Youth Soccer. Int J Hum Mov Sci. 2015;9(2):25-38.

[11] Lee AC, Lee ZC. Injury Profile of Contact-Sports for Perak Athletes in Malaysia. Int J Acad Res Bus Soc Sci [Internet]. 2018;8(9):965-76. Available from: http://hrmars.com/inde x.php/pages/detail/IJARBSS

[12] Abernethy L, MacAuley D, McNally O, McCann S. Immediate care of school sport injury. Inj Prev. 2003;9:270-3.

[13] Andersen JC, Courson RW, Kleiner DM, Mcloda TA. National Athletic Trainers' Association Position Statement: Emergency Planning in Athletics. J Athl Train. 2002;37(1):99-104.

[14] Goduhan AK, Kshirsagar AY, Zagade TB. A Study to Determine the Effectiveness of Basic Life Support Training Life Saving Skills among College Students in Selected Colleges at Jaipur for Degree Students. Int J Sci Res. 2017;6(6):2724-35.

[15] Lynn J, Id S, Schuller H, Fuchs PC, Bagheri M, Grigutsch D, et al. Basic life support knowledge in Germany and the influences of demographic factors. PLoS One [Internet]. 2020;15(8):1-13. Available from: http://dx.doi.org/10.137 1/journal.pone. 0237751

[16] Bajracharya S, Nagarkoti L. Knowledge Regarding Basic Life Support Among Nurses of a Tertiary Level Hospital of Nepal. MJSBH. 2016;15(1):66-9.

[17] Mayanlambam P, Devi AM. Knowledge and Practice Regarding Basic Life Support among Nursing Students. Int J Res Rev. 2016;3(1):43-7.
[18] Santos S V, Margarido MRRA, Caires IS, Santos RAN, Souza SG, Souza JMA. Basic life support knowledge of fi rst-year university students from Brazil. Brazilian J Med Biol Res. 2015;48(12):1151-5.

[19] Somaraj V, Shenoy RP, Panchmal GS, Jodalli PS, Sonde L Knowledge, attitude and anxiety pertaining to basic life support and medical emergencies among dental interns in Mangalore City, India. World J Emerg Med. 2017;8(2):131-5

[20] Courtenay C. Stewart-Reiner. The Psychological Parameters of Athletic Injuries in Female Collegiate Athletes. Int J Hum Mov Sport Sci. 2020; 8(1): 32-36. DOI: 10.13189/saj.2020.080104

[21] Albrecht JM, Strand BN. Basic First Aid Qualifications and Knowledge Among Youth Sport Coaches. J Coach Educ. 2010;3(3):1-18.

[22] Strand B, Lyman KJ, David S. High School Coaches' Knowledge of Emergency Care. J Res. 2019;10(2):33-9.

[23] Treasure DC, Maghan MT. Fundamentals of Coaching [Internet]. National Federation of State High School Associations; 2000. Available from: www.nfhs.org

[24] Al-Mohaissen MA. Knowledge and Attitudes Towards Basic Life Support Among Health Students at a Saudi Women's University. Sultan Qaboos Univ Med J. 2017;17(1):59-65.

[25] Stella MA, Wulandari PH, Adhiatama T, Subianto L, Adiba F, Mohamad B, et al. The Effect of Basic Life Support (BLS) Training in the Knowledge and Skill Level of Community in Sidodadi Village, Lawang, Indonesia. Indones $\mathbf{J}$ Anesthesiol Reanim. 2020;2(1):8-12.

[26] Tipa RO, Bobirnac G. Importance of basic life support training for first and second year medical students -a personal statement-. J Med Life. 2010;3(4):465-7.

[27] Roshana S, Kh B, Rm P, Mw S. Basic life support: knowledge and attitude of medical / paramedical professionals. World J Emerg Med. 2012;3(2):141-5.

[28] Elgammal M, Hassan I, Eltanahi N, Ibrahim H. The Effects of Repeated Sprint Training with Blood Flow Restriction on Strength, Anaerobic and Aerobic Performance in Basketball. Int J Hum Mov Sport Sci. 2020; 8(6): 462-468. DOI: 10.13189/saj.2020.080619. 